
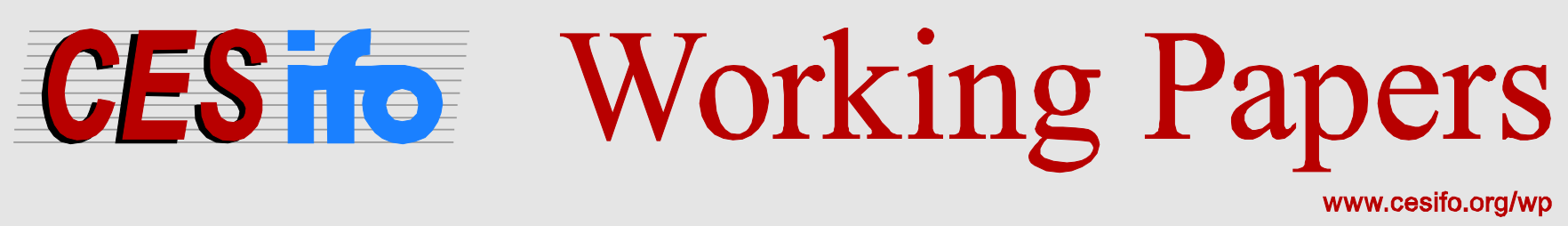

\title{
Income Dependent Equivalence Scales, Inequality, and Poverty
}

\author{
Christian Dudel \\ Jan Marvin Garbuszus \\ Notburga Ott \\ Martin Werding
}

CESIFO WORKING PAPER NO. 5568

CATEgory 3: SOCIAL PROTECTION

OCTOBER 2015

An electronic version of the paper may be downloaded

- from the SSRN website: Www.SSRN.com

- from the RePEc website: Www.RePEc.org

- from the CESifo website: www.CESifo-group.org/wp 


\title{
Income Dependent Equivalence Scales, Inequality, and Poverty
}

\begin{abstract}
Most equivalence scales which are applied in research on poverty and inequality do not depend on income, although there is strong empirical evidence that equivalence scales in fact are income dependent. This paper explores the consistency of results derived from income independent and income dependent scales. It is shown that scales of both types inevitably lead to differing assessments of poverty and inequality under quite general conditions. German microdata will be used to demonstrate and illustrate our findings. Our results provide evidence that income independent scales should be replaced with income dependent equivalence scales.
\end{abstract}

JEL-Codes: C180, D100, I320.

Keywords: equivalence scales, independence of base, income dependence.

\author{
Christian Dudel \\ Ruhr University Bochum \\ Faculty of Social Science \\ Bochum / Germany \\ christian.dudel@ruhr-uni-bochum.de \\ Notburga Ott \\ Ruhr University Bochum \\ Chair in Social Policy and Public Finance \\ Bochum / Germany \\ notburga.ott@ruhr-uni-bochum.de
}

\author{
Jan Marvin Garbuszus \\ Ruhr University Bochum \\ Chair in Social Policy and Public Finance \\ Bochum / Germany \\ jan.garbuszus@ruhr-uni-bochum.de \\ Martin Werding \\ Ruhr University Bochum \\ Chair in Social Policy and Public Finance \\ Bochum / Germany \\ martin.werding@ruhr-uni-bochum.de
}




\section{Introduction}

Equivalence scales are used to make income of households of different size and composition comparable. A well-known example is the modified OECD scale (Hagenaars et al., 1994). The household of a single adult is used as reference and a weight of 1 is assigned to it. Adding an adult to the household increases the weight by 0.5 and adding a child below age 14 increases the weight by 0.3 . For example, the weight of a household consisting of two adults and two children is 2.1. Dividing household income by such a weight yields equivalent income (or equivalized income), which is assumed to be directly comparable across households.

The modified OECD scale and other similar equivalence scales find widespread use, as they are easy to apply, and they are commonly utilized in research and even in the design of actual policies. Application of equivalence scales has limitations, though. For example, equivalence scales rest on rather strong assumptions (e.g., Blundell and Lewbel, 1991; Nelson, 1993) and results of empirical analyses are sensitive with respect to the choice of a specific equivalence scale (e.g., Buhmann et al., 1988; Szelky et al., 2004).

Most applications of equivalence scales ignore income dependence, for which there is ample evidence (e.g. Donaldson and Pendakur, 2004; Koulovatianos et al., 2005a). Income independence means that for all households of the same type the same weight is used, e.g. all households of couples with one child are assigned the weight 2.1, irrespective of whether household income is low or high. Income dependence implies that two households of the same type are assigned different weights if they have different incomes. For instance, a household consisting of a couple with one child and household income of 2,000 Euro could be assigned the weight 2.4, while a couple with one child and household income of 3,000 Euro could be assigned the weight 2.0. The intuition behind this is that high income households may spend more on goods for which economies of scale and scope are relatively high, while low income households spend more on goods with relatively low economies of scale and scope.

This paper explores the consequences of applying income independent scales when "true" equivalence scales are income dependent. Specifically, it will be analyzed what information can be recovered in this case by the application of income independent equivalence scales. We will consider effects for equivalent household income and for aggregate measures of poverty and inequality. At the household level, we will look at absolute levels of equivalent income, the resulting ordering of households, and the interpretation of equivalent income when income independent equivalence scales are utilized, while income dependent scales would be appropriate. Equivalent income of individual households is often not of primary interest, but the issues covered in our 
analysis are the basis for aggregate-level measurement of both poverty and inequality. We will assess the effects at this level looking at income distributions and Lorenz curves.

Our results indicate that income independent and income dependent equivalence scales are compatible neither at the household level nor at the aggregate level. While sensitivity of empirical results with respect to the choice of a specific equivalence scale has long been established (e.g. Coulter et al., 1992), the relevant literature focuses on different income independent scales and relies on rather strong assumptions. Our results extend to income dependent equivalence scales and help to explain sensitivity under milder assumptions.

Most importantly, we will demonstrate that, if equivalence scales are income dependent, it is not possible to find an income independent scale which leads to the same assessments regarding equivalent incomes, inequality and poverty, except for some rather specific special cases. In the light of empirical evidence on income dependence of equivalence scales (see section 2.3), researchers and policy makers need to reconsider standard practices. They should definitely be cautious about the use of income independent scales.

The remainder of this paper is structured as follows. Equivalence scales, income dependence, and the empirical evidence on income dependence will be discussed in section 2 . In section 3 the consistency of income independent scales and income dependent scales is explored at the household level, while section 4 covers aggregate measurement of poverty and inequality. Section 5 concludes.

\section{Equivalence scales}

\subsection{Definition}

Let $\mathbf{z}=\left(z_{1}, z_{2}, \ldots, z_{k}\right)$ denote a vector of $k$ household characteristics like, for example, household size and age of household members. Any household can choose between $m$ goods with prices $\mathbf{p}=\left(p_{1}, p_{2}, \ldots, p_{m}\right)$. Demand is captured by a vector $\mathbf{q}=\left(q_{1}, q_{2}, \ldots, q_{m}\right)$ given by the demand function $\mathrm{D}(\mathbf{p}, \mathbf{z}, x)$, where $x$ is household income. The demand function can be derived from the household utility function $\mathrm{U}(\mathbf{q}, \mathbf{z}){ }^{1}$ Finally, the cost function is given by $\mathrm{C}(\mathbf{p}, \mathbf{z}, u)=\min _{\mathbf{q}}\left[\mathbf{p}^{\prime} \mathbf{q} \mid \mathrm{U}(\mathbf{q}, \mathbf{z})=u\right]$ and is assumed to be nondecreasing in $u$.

\footnotetext{
${ }^{1}$ Note that household utility functions ignore the distribution of resources inside the household and may be hard to defend, as it is individual household members who derive utility from consumption (Ott, 1992; Phipps and Burton, 1995). Acknowledging for individual needs and preferences as well as intrafamily bargaining in deriving equivalence scales is an unsolved problem and beyond the scope of this paper. For simplicity, we will assume identical individual utility functions and equal welfare for all household members.
} 
Definition 2.1. Equivalence scales are defined as the ratio of two cost functions $\mathrm{C}(\mathbf{p}, \mathbf{z}, u) / \mathrm{C}\left(\mathbf{p}, \mathbf{z}_{r}, u\right)$, where $\mathbf{z}_{r}$ denotes household characteristics of the reference household. They will be denoted as $\mathrm{A}\left(\mathbf{p}, \mathbf{z}, \mathbf{z}_{r}, u\right)$. A specific value returned by the function $\mathrm{A}(\cdot)$ for specific values of $\mathbf{p}, \mathbf{z}, \mathbf{z}_{r}$, and $u$ will be called equivalence weight.

An equivalence scale is thus a function returning the ratio of expenditure of two households of different composition with the same level of utility. ${ }^{2}$ By this definition, equivalence scales depend on prices, the types of households which are compared, and the utility level $u$.

In the literature it is often assumed that equivalence scales do not depend on $u$. This assumption is called independence of base (Lewbel, 1989; Blundell and Lewbel, 1991) or equivalence scale exactness (Blackorby and Donaldson, 1993).

Definition 2.2. Equivalence scales for which $\mathrm{A}\left(\mathbf{p}, \mathbf{z}, \mathbf{z}_{r}, u\right)=\mathrm{A}\left(\mathbf{p}, \mathbf{z}, \mathbf{z}_{r}\right)$ are called base independent scales.

The assumption of base independence is convenient in two respects. First, it simplifies identification of equivalence scales and eases empirical estimation considerably. Second, base independent equivalence scales do not depend on household income or expenditure and the number of equivalence weights will equal the number of household types, so that they can be applied with little effort.

Throughout, two basic assumptions on equivalence scales - whether base independent or not - will be maintained.

Assumption 2.1. The reference household type $\mathbf{z}_{r}$ is fixed to the household type with the smallest needs.

Assumption 2.2. Dependency on prices can be ignored, such that it suffices to write equivalence scales as $\mathrm{A}\left(\mathbf{z}, \mathbf{z}_{r}, u\right)$.

Assumption 2.1 means that the same reference household is used for each comparison. The household type with the smallest needs will usually be households of single persons (or a subset of these). As a consequence $\mathrm{A}\left(\mathbf{p}, \mathbf{z}, \mathbf{z}_{r}, u\right) \geq 1$ for each $\mathbf{z} \neq \mathbf{z}_{r}$. This avoids difficulties which can arise in the context of inequality analyses if equivalent income depends on the choice of reference households (Ebert and Moyes, 2003). Assumption 2.2 can easily be justified if analysis is restricted to households living at a certain time and in a certain region, such that all households face the same prices. ${ }^{3}$ Because of assumptions 2.1 and 2.2 it is sufficient to write equivalence scales as $\mathrm{A}(\mathbf{z}, u)$ or as $\mathrm{A}(\mathbf{z})$ in case of base independence.

\footnotetext{
${ }^{2}$ We restrict attention to relative equivalence scales and leave out absolute equivalence scales (see Donaldson and Pendakur, 2006), as the former are most common in applied analyses.

${ }^{3}$ Problems which may arise if dependency on prices is dropped in analyses covering several time periods are discussed by Pendakur (2002).
} 
Moreover, we assume that the following budget constraint holds, which is necessary to apply equivalence scales to household income, as it is commonly done in applied research:

Assumption 2.3. For each household expenditure equals income, $\mathbf{p}^{\prime} \mathbf{q}=x$.

Assumption 2.3 does not rule out saving, which can be included as an additional good. Alternatively, one could replace the cost function with an income function $\mathrm{I}(\mathbf{z}, u)=\min _{x}[x \mid \mathrm{V}(\mathbf{z}, x)=u]$, where $\mathrm{V}(\mathbf{z}, x)$ is the indirect utility function of a household with characteristics $\mathbf{z}$ and income $x$ facing prices $\mathbf{p}$, which is assumed to be strictly increasing in $x$. I(·) gives the minimum income needed to achieve utility level $u$ given prices $\mathbf{p}$ and composition $\mathbf{z}$.

As an example, consider how base independence and assumption 2.3 work together. Let $x^{\prime}$ denote observed income of a household of type $\mathbf{z}$. Dividing $x^{\prime}$ by $\mathrm{A}(\mathbf{z})$ gives $x_{r}$, i.e., the income of the reference household that has the same utility level. This works because observed income $x^{\prime}$ equals $\mathrm{C}(\mathbf{z}, u)$ by assumption. Dividing this by $\mathrm{A}(\mathbf{z})$ gives $\mathrm{C}\left(\mathbf{z}_{r}, u\right)$ in the case of base independence. By assumption $\mathrm{C}\left(\mathbf{z}_{r}, u\right)$ equals equivalent income $x_{r}$. This also works the other way round and one could multiply $x_{r}$ with $\mathrm{A}(\mathbf{z})$ to calculate $x^{\prime}$.

\subsection{Income dependent equivalence scales}

One may wonder whether the assumption of base independence as introduced in definition 2.2 is reasonable. There are specific utility functions which imply independence of base (Lewbel, 1989). Nevertheless, from a theoretical point of view this assumptions is rather restrictive. Conniffe (1992) analyzes the Extended Linear Expenditure System (Lluch, 1973) and the Almost Ideal Demand System (Deaton and Muellbauer, 1980) as two common approaches to modeling household demand and argues that they both lead to equivalence scales which depend on the level of utility (see Schröder 2004 for another example).

More generally, replacing $u$ in definition 2.1 with the indirect utility function $\mathrm{V}\left(\mathbf{z}_{r}, x_{r}\right)$, where $x_{r}$ is income of the reference household, equivalence scales can be written as functions of income of the reference household.

Definition 2.3. An equivalence scale written as a function of $x_{r}, \mathrm{~A}\left[\mathbf{z}, \mathrm{V}\left(\mathbf{z}_{r}, x_{r}\right)\right]$, and defined by $\mathrm{C}\left[\mathbf{z}, \mathrm{V}\left(\mathbf{z}_{r}, x_{r}\right)\right] / x_{r}$ will be called income dependent if $\mathrm{A}\left[\mathbf{z}, \mathrm{V}\left(\mathbf{z}_{r}, x_{r}^{\prime}\right)\right] \neq$ $\mathrm{A}\left[\mathbf{z}, \mathrm{V}\left(\mathbf{z}_{r}, x_{r}^{\prime \prime}\right)\right]$ for at least two incomes $x_{r}^{\prime} \neq x_{r}^{\prime \prime}$.

If income dependent equivalence scales are defined by replacing $u$ with $\mathrm{V}(\mathbf{z}, x)$, where $x$ is the income of a household of type $\mathbf{z} \neq \mathbf{z}_{r}$, then $\mathrm{A}[\mathbf{z}, \mathrm{V}(\mathbf{z}, x)]$ will be used to denote income dependent scales and is defined as $x / \mathrm{C}\left[\mathbf{z}_{r}, \mathrm{~V}(\mathbf{z}, x)\right]$. Dividing 
household income $x$ of a household with characteristics $\mathbf{z}$ by the appropriate income dependent equivalence weight will thus recover $\mathrm{C}\left[\mathbf{z}_{r}, \mathrm{~V}(\mathbf{z}, x)\right]$, i.e. the income a reference household needs to attain the same welfare as the household with characteristics z. If $\mathrm{V}\left(\mathbf{z}_{r}, x_{r}\right)=\mathrm{V}(\mathbf{z}, x)$ then $\mathrm{A}[\mathbf{z}, \mathrm{V}(\mathbf{z}, x)]=\mathrm{A}\left[\mathbf{z}, \mathrm{V}\left(\mathbf{z}_{r}, x_{r}\right)\right]$ which allows to switch perspective from $\mathbf{z}$ to $\mathbf{z}_{r}$ and vice versa.

As can be seen from definition 2.3 base independence implies independence of income and requires that the derivative of $\mathrm{C}\left[\mathbf{z}, \mathrm{V}\left(\mathbf{z}_{r}, x_{r}\right)\right]$ with respect to $x_{r}$ is constant,

$$
\frac{\partial \mathrm{C}\left[\mathbf{z}, \mathrm{V}\left(\mathbf{z}_{r}, x_{r}\right)\right]}{\partial \mathrm{V}\left(\mathbf{z}_{r}, x_{r}\right)} \frac{\partial \mathrm{V}\left(\mathbf{z}_{r}, x_{r}\right)}{\partial x_{r}}=\mathrm{A}(\mathbf{z})
$$

Both derivatives on the left hand side are non-negative, with $\partial \mathrm{C}\left[\mathbf{z}, \mathrm{V}\left(x_{r}\right)\right] / \partial \mathrm{V}\left(x_{r}\right) \geq 0$ and $\partial \mathrm{V}\left(\mathbf{z}_{r}, x_{r}\right) / \partial x_{r}>0$, but without additional assumptions they will depend on $x_{r}$. Their product is thus not necessarily constant and each change in utility $\mathrm{V}\left(\mathbf{z}_{r}, x_{r}\right)$ has to be offset by a corresponding change in expenditure $\mathrm{C}\left[\mathbf{z}, \mathrm{V}\left(\mathbf{z}_{r}, x_{r}\right)\right]$ to guarantee independence of income.

This implies that adding a person to a reference household with household income of 1,500 Euro would increase the income needed by the same relative amount as if a person is added to a reference household with 5,000 Euro of household income. This may not be realistic, however, as a richer reference household may, for example, have much more housing space and may not need much more in addition. Also, the restriction of base independence means that adding a person to a richer household is more costly in absolute terms than in the case of a poor household. This may be undesirable from a normative perspective, for instance, when equivalence scales are used to measure the cost of children and to design child-related tax allowances or other child benefits.

\subsection{Evidence on income dependence}

Empirical evidence regarding income (in-)dependence can be found in numerous studies. ${ }^{4}$ Independence of base has been rejected in virtually all studies we are aware of. $^{5}$ In some cases rejection is only by a small margin (Blundell and Lewbel, 1991; Lancaster and Ray, 1998), or results depend on the proxy used for household welfare (Jones and O'Donnel, 1995; Pendakur, 1999). Quite generally, equivalence scales are

\footnotetext{
${ }^{4}$ Besides the contributions that are cited in the following, a list which is not necessarily complete includes Dickens et al. (1993), Pashardes (1995), Plug and van Praag (1995), Gozalo (1997), Kalwij et al. (1998), Lyssiotou (2003), Donaldson and Pendakur (2004), Koulovatianos et al. (2005b), and de Ree et al. (2013).

${ }^{5}$ A notable exception confirming base independence is the analysis by Koohi-Kamali (2013) who studies demand under wartime rationing and thus a rather special case.
} 


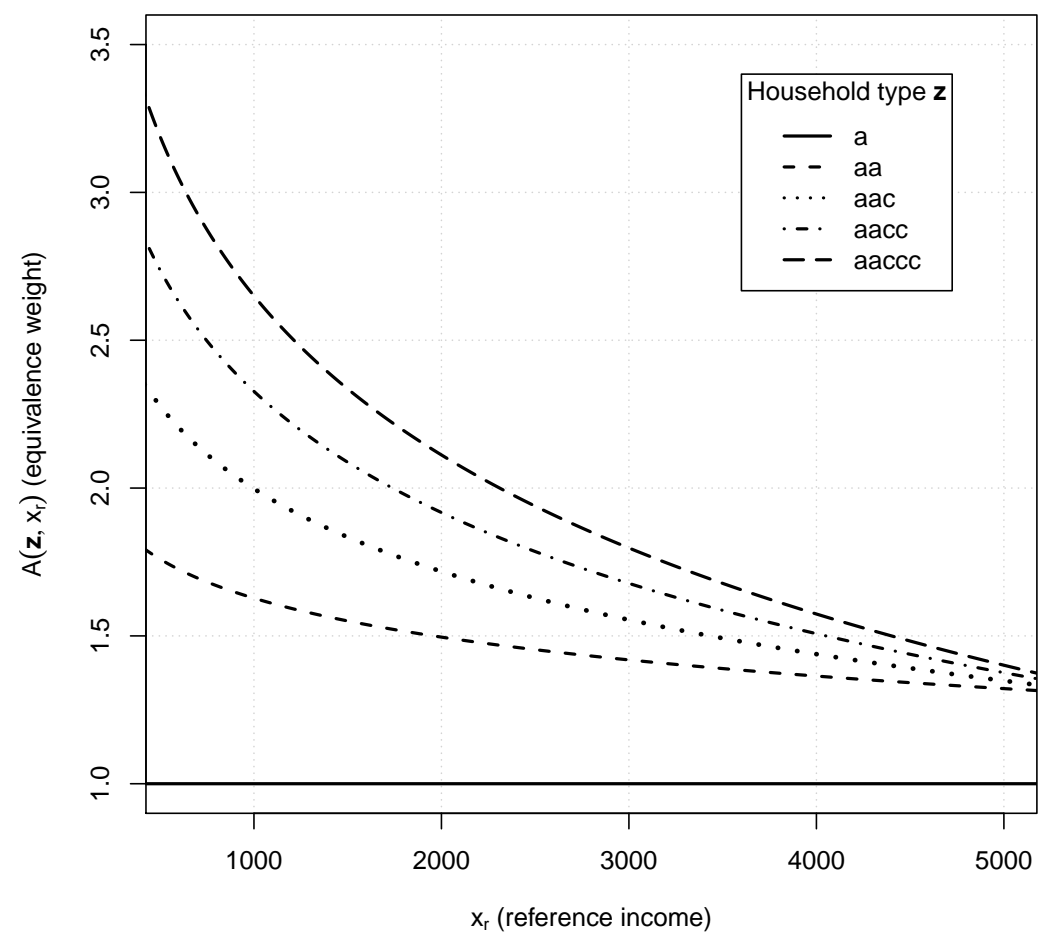

Figure 1: Income dependent equivalence scale derived from Koulovatianos et al. (2005a), by reference income $x_{r}$ and household type $\mathbf{z}$.

Note: 'a' represents adult members and 'c' children aged between 7 and 11 years living in a household. For example, 'aacc' denotes a couple with two children (in this age bracket).

declining with income. ${ }^{6}$

Aaberge and Melby (1998), Donaldson and Pendakur (2006), and Balli and Tiezzi (2013) compare results for the Gini coefficient using income independent and income dependent equivalence scales; Juhasz and Biewen (2014) compare results for the low-income proportion, the Gini coefficient, and the Theil index. While the results of Donaldson and Pendakur (2006) and Juhasz and Biewen (2014) indicate that inequality and poverty are lower in case of income dependent equivalence scales compared to base independent scales, results of Aaberge and Melby (1998) and Balli and Tiezzi (2013) show considerably higher inequality. Furthermore, Aaberge and Melby (1998) and Donaldson and Pendakur (2006) find time trends in inequality to be affected, while this is not the case for Balli and Tiezzi (2013).

An example of an income dependent equivalence scale is shown in figure 1, which is derived from results for Germany reported in Koulovatianos et al. (2005a). Koulovatianos et al. (2005a) asked respondents for their assessments of income needed

\footnotetext{
${ }^{6}$ The results reported by Juhasz and Biewen (2014) are an exception; there, equivalence scales increase with income for some types of households.
} 
by households of different composition, using the household of a single person with given income as a reference. Five different levels of reference income were used: 605 Euro, 1,513 Euro, 2, 420 Euro, 3, 328 Euro, and 4,236 Euro (2010 values). ${ }^{7}$ Results shown in figure 1 are estimates derived from regressing log household income on equivalence weights. They give a good fit to the weights reported by Koulovatianos et al. (2005a). Irrespective of the household type considered, equivalence scales are declining with income. For instance, a couple with two children and a household income of 2,327 Euro is comparable in terms of household welfare to a single person with 1,000 Euro, implying an equivalence weight of about 2.33, while a couple with two children and household income of 6,030 Euro is comparable to a single person with 4,000 Euro, implying an equivalence weight of 1.51 .

\section{Consistency of income (in-)dependent scales}

Despite overwhelming evidence that equivalence scales are income dependent, possible consequences of applying income independent scales have not been explored in depth. In this section, we focus on effects for the absolute level of equivalent income and for the ordering of households by this income. In addition, we will comment on the interpretation of equivalent income. Throughout, we assume that true equivalence scales are income dependent, in line with virtually all empirical evidence (see section $2.3)$.

Both the absolute level and the ordering of equivalent income at the household level are rather simple notions, but they are closely connected to measurement of poverty and inequality. Most poverty measures rely on an assessment of whether household income is higher or lower than some poverty threshold, and axiomatic properties of poverty measures build on this assessment (e.g., Zheng, 1997). If two equivalence scales yield different absolute levels of equivalent income they may thus lead to different assessments of poverty. Moreover, differences in absolute levels of income may also change assessments of inequality, as will be demonstrated in section 3.2 .

Ordering of equivalent income is closely related to the transfer principle (e.g. Atkinson, 1970). If, for a given income distribution $f(z)$, a transfer $d$ is made between two households with incomes $z_{i}<z_{j}$, such that $z_{i}+d<z_{j}-d$, then the resulting income distribution $f_{d}(z)$ will be less unequal than $f(z)$. In this case, the transfer is called "progressive". The transfer principle is of eminent importance for inequality measurement, as many inequality measures are based on it (e.g. Allison, 1978). If

\footnotetext{
${ }^{7}$ Here, reference incomes originally reported by Koulovatianos et al. (2005a) have been adjusted for inflation, based on data provided by the German Federal Statistical Office.
} 
two equivalence scales give rise to different orderings of equivalent income, they may lead to different assessments of inequality. In fact, a transfer of equivalent income between two households of different types may be progressive given one equivalence scale, but regressive for another, i.e., $y_{i}^{\prime}+d<y_{j}^{\prime}-d$ but $y_{i}^{\prime \prime}+d \geq y_{j}^{\prime \prime}-d$, where $y^{\prime}$ and $y^{\prime \prime}$ denote equivalent incomes derived from two different equivalence scales. The same may happen even if the ordering of equivalent incomes is the same, due to differences in absolute levels of equivalent income.

Building on these considerations, we will use the income dependent equivalence scale for Germany derived from Koulovatianos et al. (2005a) as described in the preceding section and the modified OECD scale to provide illustrative examples. Income dependent equivalence scales will be expressed using the indirect utility function of a household of composition $\mathbf{z}, \mathrm{V}(\mathbf{z}, x)$, so that $\mathrm{A}[\mathbf{z}, \mathrm{V}(\mathbf{z}, x)]$ will be used to denote income dependent equivalence scales.

\subsection{Further assumptions}

A few additional assumptions are needed to clearly state our results, all of which are not restrictive.

Assumption 3.1. Household income has support on the open interval $\mathbb{R}_{+}=(0, \infty)$. All functions of household income have $\mathbb{R}_{+}$as domain.

Assumption 3.2. Equivalence scales are continuous and strictly decreasing in income, such that $\mathrm{A}[\mathbf{z}, \mathrm{V}(\mathbf{z}, x)]<\mathrm{A}\left[\mathbf{z}, \mathrm{V}\left(\mathbf{z}, x^{\prime}\right)\right]$ for $x>x^{\prime}$.

Assumption 3.3. For some specific income $x_{\mathbf{z}}^{*} \in \mathbb{R}_{+}$, scale weights derived from income independent and income dependent equivalence scales are equal, i.e., $\mathrm{A}(\mathbf{z})=$ $\mathrm{A}\left[\mathbf{z}, \mathrm{V}\left(\mathbf{z}, x_{\mathbf{z}}^{*}\right)\right]$, where $x_{\mathbf{z}}^{*}$ is not necessarily the same for all household types.

Assumption 3.4. For two household types $\mathbf{z}_{1}$ and $\mathbf{z}_{2}$, either $\mathrm{A}\left[\mathbf{z}_{1}, \mathrm{~V}\left(\mathbf{z}_{1}, x\right)\right] \geq$ $\mathrm{A}\left[\mathbf{z}_{2}, \mathrm{~V}\left(\mathbf{z}_{2}, x\right)\right]$ or $\mathrm{A}\left[\mathbf{z}_{1}, \mathrm{~V}\left(\mathbf{z}_{1}, x\right)\right] \leq \mathrm{A}\left[\mathbf{z}_{2}, \mathrm{~V}\left(\mathbf{z}_{2}, x\right)\right]$ holds on the support of $x$; there is at least one $x \in \mathbb{R}_{+}$with $\mathrm{A}\left[\mathbf{z}_{1}, \mathrm{~V}\left(\mathbf{z}_{1}, x\right)\right] \neq \mathrm{A}\left[\mathbf{z}_{2}, \mathrm{~V}\left(\mathbf{z}_{2}, x\right)\right]$.

The support assumption 3.1 restricts income to be positive and finite. This assumption will be maintained throughout, as it rules out division by zero in some cases (implying that the corresponding equivalence weight would not be defined).

Assumption 3.2 formally states that equivalence weights decline as income increases. $^{8}$

\footnotetext{
${ }^{8}$ Implications for equivalence weights which are strictly increasing in income follow easily from the results derived here.
} 
Assumption 3.3 implies that income independent and income dependent scales intersect. If this condition does not apply, income independent scales have no meaningful interpretation. Given an income dependent equivalence scale and an income independent equivalence scale it can easily be assessed whether this assumption holds. This will be discussed further in section 3.4.

Assumption 3.4 rules out that the curves defined by equivalence weights for different types of households intersect. The income dependent equivalence scale in figure 1 offers an example. Intersection would imply that type- $\mathbf{z}_{1}$ households need less than type- $\mathbf{z}_{2}$ households at low levels of income, but more at high levels. This would be rather counterintuitive.

\subsection{Absolute level of equivalent income}

For a household of type $\mathbf{z} \neq \mathbf{z}_{r}$ income $x$ is observed and equivalent income is to be determined. Application of the true income dependent equivalence scale $\mathrm{A}[\mathbf{z}, \mathrm{V}(\mathbf{z}, x)]$ would recover equivalent income $\mathrm{C}\left[\mathbf{z}_{r}, \mathrm{~V}(\mathbf{z}, x)\right]$. But what is the result if an income independent scale $\mathrm{A}(\mathbf{z})$ is applied instead?

Proposition 3.1. Let assumptions 3.1 and 3.3 hold. Dividing $x$ by $\mathrm{A}(\mathbf{z})$ results in

$$
\tilde{\mathrm{C}}\left[\mathbf{z}_{r}, \mathrm{~V}(\mathbf{z}, x)\right]=\mathrm{B}\left(x, x_{\mathbf{z}}^{*}, \mathbf{z}\right) \mathrm{C}\left[\mathbf{z}_{r}, \mathrm{~V}(\mathbf{z}, x)\right],
$$

where $\mathrm{B}\left(x, x_{\mathbf{z}}^{*}, \mathbf{z}\right)=\mathrm{A}[\mathbf{z}, \mathrm{V}(\mathbf{z}, x)] / \mathrm{A}\left[\mathbf{z}, \mathrm{V}\left(\mathbf{z}, x_{\mathbf{z}}^{*}\right)\right]$.

$\tilde{\mathrm{C}}\left[\mathbf{z}_{r}, \mathrm{~V}(\mathbf{z}, x)\right]$ is used to denote the "cost function" which is recovered assuming base independence, and $\mathrm{B}\left(x, x_{\mathbf{z}}^{*}, \mathbf{z}\right)$ will be called relative bias, as it equals $\tilde{\mathrm{C}}\left[\mathbf{z}_{r}, \mathrm{~V}(\mathbf{z}, x)\right] / \mathrm{C}\left[\mathbf{z}_{r}, \mathrm{~V}(\mathbf{z}, x)\right]$ by definition. Proposition 3.1 shows that true equivalent income $\mathrm{C}\left[\mathbf{z}_{r}, \mathrm{~V}(\mathbf{z}, x)\right]$ is downscaled by the equivalence weight for household income $x^{*}$ and upscaled by the equivalence weight for household income $x$, with $\tilde{\mathrm{C}}\left[\mathbf{z}_{r}, \mathrm{~V}(\mathbf{z}, x)\right]=\mathrm{C}\left[\mathbf{z}_{r}, \mathrm{~V}(\mathbf{z}, x)\right]$ only if $x=x_{\mathbf{z}}^{*}$.

Furthermore, $\mathrm{B}\left(x, x_{\mathbf{z}}^{*}, \mathbf{z}\right)$ depends on income, choice of the income independent scale, and household type. Given a specific income independent equivalence scale, $x_{\mathbf{z}}^{*}$ is fixed and the magnitude of the bias only depends on income and household type. Figure 2 shows magnitudes of errors arising under the assumption that the scale derived from Koulovatianos et al. (2005a) is true, but the modified OECD scale is applied. For example, a childless couple with observed household income of 1,500 Euro is assigned an equivalent income of 1,000 Euro by the OECD scale, while true equivalent income amounts to 912 Euro. The latter is thus exaggerated by a factor of about 1.1. More generally, low equivalent incomes will be biased upwards and high equivalent incomes will be biased downwards, which implies an underestimation 


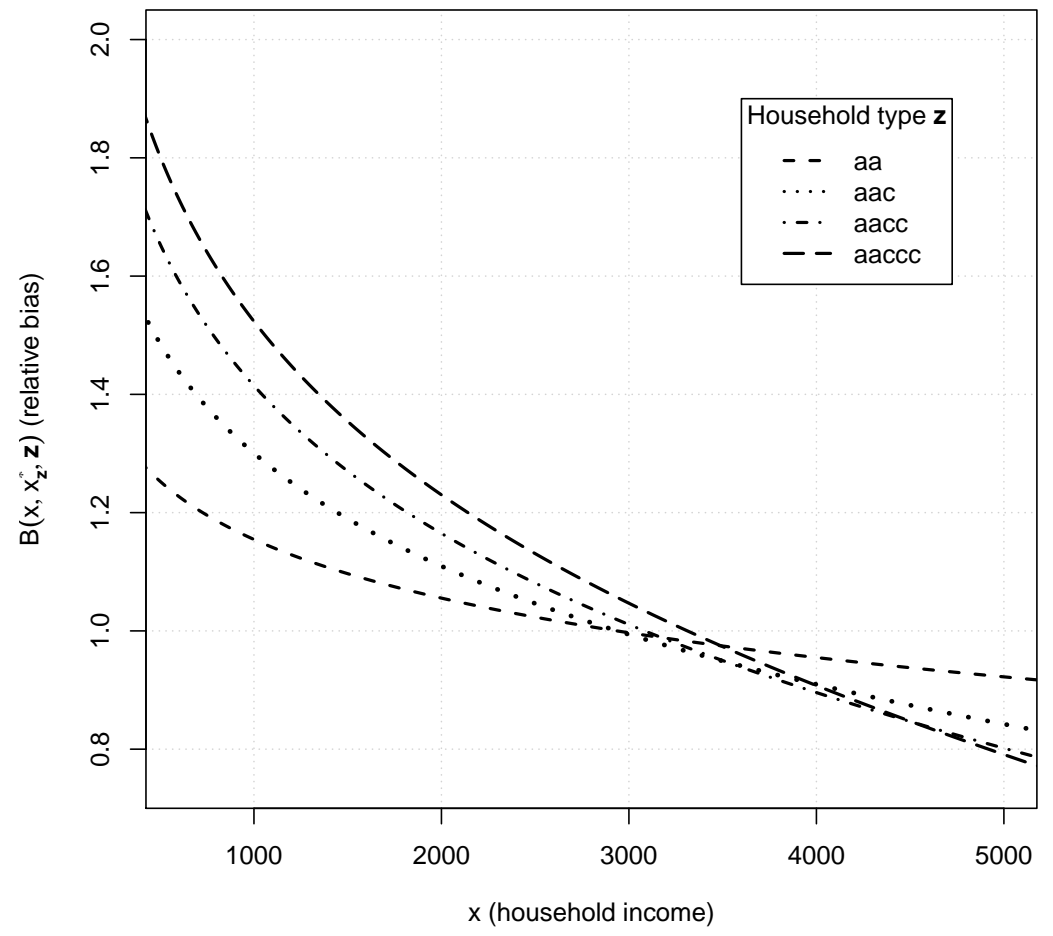

Figure 2: Relative bias $\mathrm{B}\left(x, x_{\mathbf{z}}^{*}, \mathbf{z}\right)$, depending on household type $\mathbf{z}$ and income $x$.

Note: Calculations are based on income dependent scales for Germany derived from Koulovatianos et al. (2005a) and the modified OECD scale.

of inequality (see section 4.2). Other income independent scale could have a smaller bias at low incomes, but this would necessarily increase the bias for higher incomes.

\subsection{Ordering of equivalent income}

Using income independent equivalence scales where income dependent ones would be appropriate, the absolute level of equivalent income can not be recovered, but one could still try to arrive at an ordering of households by equivalent income. Equivalent incomes of two households of the same type $\mathbf{z}$ and with household incomes $x^{\prime}$ and $x^{\prime \prime}$ can be compared without problems if assumptions 3.1 and 3.2 hold. Any strict equality or strict inequality between $x^{\prime}$ and $x^{\prime \prime}$ carries over to both true equivalent income and equivalent income derived from an income independent equivalence scale. For example, $\mathrm{C}\left[\mathbf{z}_{r}, \mathrm{~V}\left(\mathbf{z}, x^{\prime}\right)\right]>\mathrm{C}\left[\mathbf{z}_{r}, \mathrm{~V}\left(\mathbf{z}, x^{\prime \prime}\right)\right]$ will only hold if $x^{\prime}>x^{\prime \prime}$, which obviously implies $\tilde{\mathrm{C}}\left[\mathbf{z}_{r}, \mathrm{~V}\left(\mathbf{z}, x^{\prime}\right)\right]>\tilde{\mathrm{C}}\left[\mathbf{z}_{r}, \mathrm{~V}\left(\mathbf{z}, x^{\prime \prime}\right)\right]$.

This is generally not the case, if households of different types $\mathbf{z}_{1}$ and $\mathbf{z}_{2}$ are to be compared. Let $x_{1}$ denote income of the type- $\mathbf{z}_{1}$ household and $x_{2}$ the income of the type- $\mathbf{z}_{2}$ household. 
Proposition 3.2. Let assumptions 3.1, 3.2, and 3.4 hold. For any two household types $\mathbf{z}_{1}$ and $\mathbf{z}_{2}$ there exist incomes $x_{1}$ and $x_{2}$ such that

$$
\mathrm{C}\left[\mathbf{z}_{r}, \mathrm{~V}\left(\mathbf{z}_{2}, x_{2}\right)\right]>\mathrm{C}\left[\mathbf{z}_{r}, \mathrm{~V}\left(\mathbf{z}_{1}, x_{1}\right)\right] \text { and } \tilde{\mathrm{C}}\left[\mathbf{z}_{r}, \mathrm{~V}\left(\mathbf{z}_{2}, x_{2}\right)\right]<\tilde{\mathrm{C}}\left[\mathbf{z}_{r}, \mathrm{~V}\left(\mathbf{z}_{1}, x_{1}\right)\right]
$$

Such inversions will not occur only if $\mathrm{A}\left[\mathbf{z}_{1}, \mathrm{~V}\left(\mathbf{z}_{1}, x\right)\right]=\mathrm{G}\left(\mathbf{z}_{1}\right) \mathrm{K}(x), \mathrm{A}\left[\mathbf{z}_{2}, \mathrm{~V}\left(\mathbf{z}_{2}, x\right)\right]=$ $\mathrm{G}\left(\mathbf{z}_{2}\right) \mathrm{K}\left(\mathrm{G}\left(\mathbf{z}_{1}\right) / \mathrm{G}\left(\mathbf{z}_{2}\right) x\right)$ and $\mathrm{G}\left(\mathbf{z}_{2}\right) / \mathrm{G}\left(\mathbf{z}_{1}\right)=\mathrm{A}\left(\mathbf{z}_{2}\right) / \mathrm{A}\left(\mathbf{z}_{1}\right)$. If $\mathbf{z}_{1}=\mathbf{z}_{r}$ and $\mathbf{z}_{2} \neq \mathbf{z}_{r}$, inversions will always occur.

A complete proof is provided in the appendix. Note that assumption 3.2 could be changed to correspond to the case of strictly increasing scales, and the proposition would still hold.

Proposition 3.2 implies that the true ordering of equivalent incomes can not be recovered under quite general conditions. The shape restriction in proposition 3.2 means that, for all non-reference household types, income dependent equivalence weights have to be of the same shape $\mathrm{K}(x)$ that is linearly shifted by constants $\mathrm{G}(\mathbf{z})$ depending on household type, where the ratios of these constants have to equal the ratios of income independent scales.

As a consequence of proposition 3.2, transfers which are progressive under income independent scales may in fact be regressive and vice versa. ${ }^{9}$ As an example illustrated in figure 3, consider again the modified OECD scale and the scale derived from Koulovatianos et al. (2005a) which does not conform to the shape restriction in proposition 3.2. Suppose that household income is 1,210 Euro for a childless couple and 1,966 Euro for a couple with three children. Using the modified OECD scale, division by 1.5 and 2.4 yields equivalent incomes of 807 Euro and 819 Euro, respectively, indicating that the family is slightly better off than the couple. Base dependent equivalence weights amount to 1.69 and 2.97; their application results in equivalent incomes of 716 Euro and 622 Euro, respectively. Numerous further examples for proposition 3.2 to hold could be found for other levels of income and other household types building on the same two scales.

\subsection{Interpretation of equivalent income}

Although $\tilde{\mathrm{C}}\left[\mathbf{z}_{r}, \mathrm{~V}(\mathbf{z}, x)\right]$ does not equal true equivalent income, one might still try to attach a sensible interpretation to it. On the one hand, under assumption 3.3, one could argue that all households of type $\mathbf{z}$ are treated as having income $x_{\mathbf{z}}^{*}$. Yet, this seems rather crude, since one of the intentions of using equivalence scales is accounting

\footnotetext{
${ }^{9}$ Another case for such inversions to occur was reported by Glewwe (1991) and Ebert and Moyes (2003) who study progressive transfers when household equivalent income is used to assess inequality not at the household level but at the level of individual household members.
} 


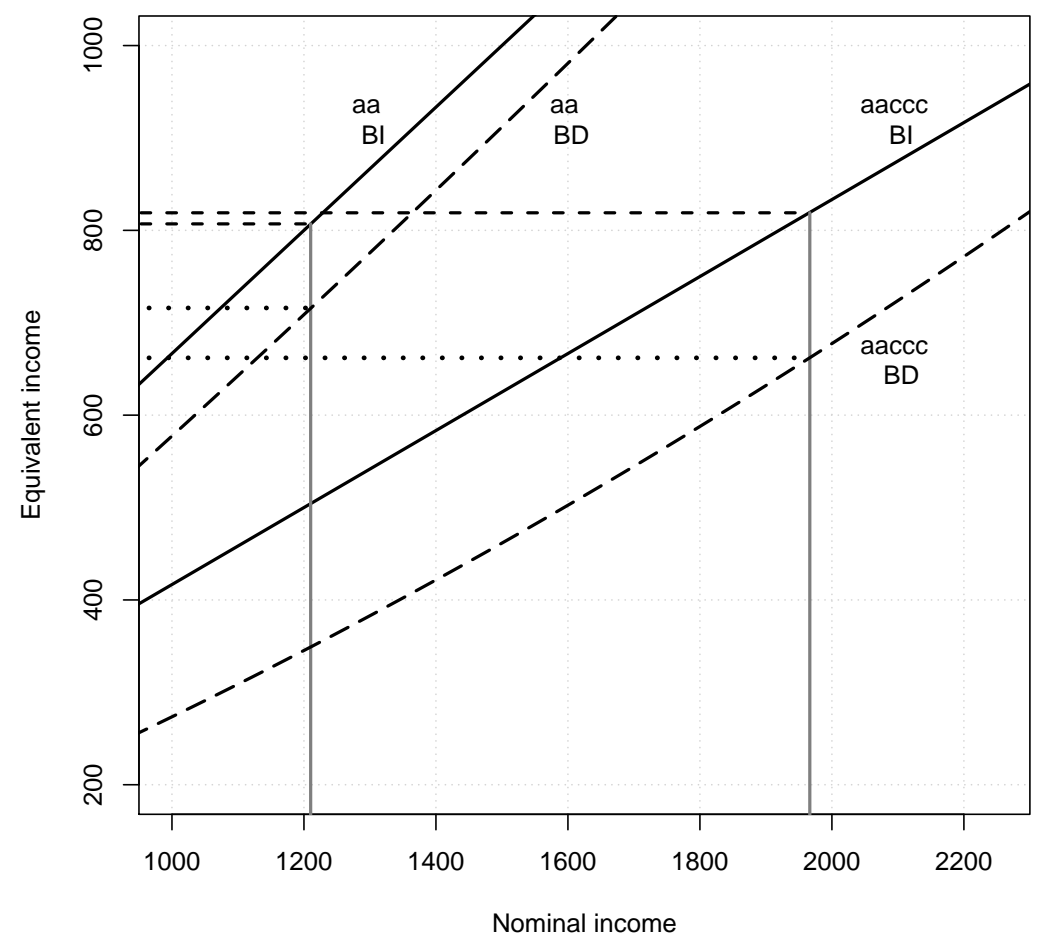

Figure 3: Household and equivalent income of childless couples (aa) and couples with three children (aaccc) using base dependent (BD) and base independent (BI) equivalence scales.

Note: Solid vertical lines indicate examples for observed household income; horizontal dotted lines indicate corresponding amounts of base dependent equivalent income; horizontal dashed lines indicate base independent equivalent income. Calculations are based on income dependent scales for Germany derived from Koulovatianos et al. (2005a) and the modified OECD scale.

for different needs, which obviously depend on income when equivalence scales are income dependent. On the other hand, depending on how the income dependent scales were derived, one could interpret $\tilde{\mathrm{C}}\left[\mathbf{z}_{r}, \mathrm{~V}(\mathbf{z}, x)\right]$ as being standardized with respect to mean income, or as using the average of income dependent equivalence weights. The former case corresponds to choosing $x_{\mathbf{z}}^{*}$ such that $\mathrm{A}(\mathbf{z})=\mathrm{A}[\mathbf{z}, \mathrm{V}(\mathbf{z}, \mathrm{E}[x \mid \mathbf{z}])]$; in the latter case, $x_{\mathbf{z}}^{*}$ is chosen such that $\mathrm{A}(\mathbf{z})=\mathrm{E}[\mathrm{A}(\mathbf{z}, \mathrm{V}[\mathbf{z}, x])]$, with an outcome that can not be distinguished from the first case. Note also that estimation methods for deriving income independent scales are not designed to yield equivalence scales obeying one of these rules.

Interpretation of results is even less clear when assumption 3.3 holds, while $x_{\mathbf{z}}^{*}$ is different for different household types. This is the case for the modified OECD scale and the scale derived from Koulovatianos et al. (2005a), as can be seen in figure 4 . There, income dependent weights are shown as solid lines; dashed lines represent the weights of the modified OECD scale and corresponding incomes $x_{\mathbf{z}}^{*}$. In the case of childless couples, the equivalence weight of the modified OECD scale amounts to 1.5, 


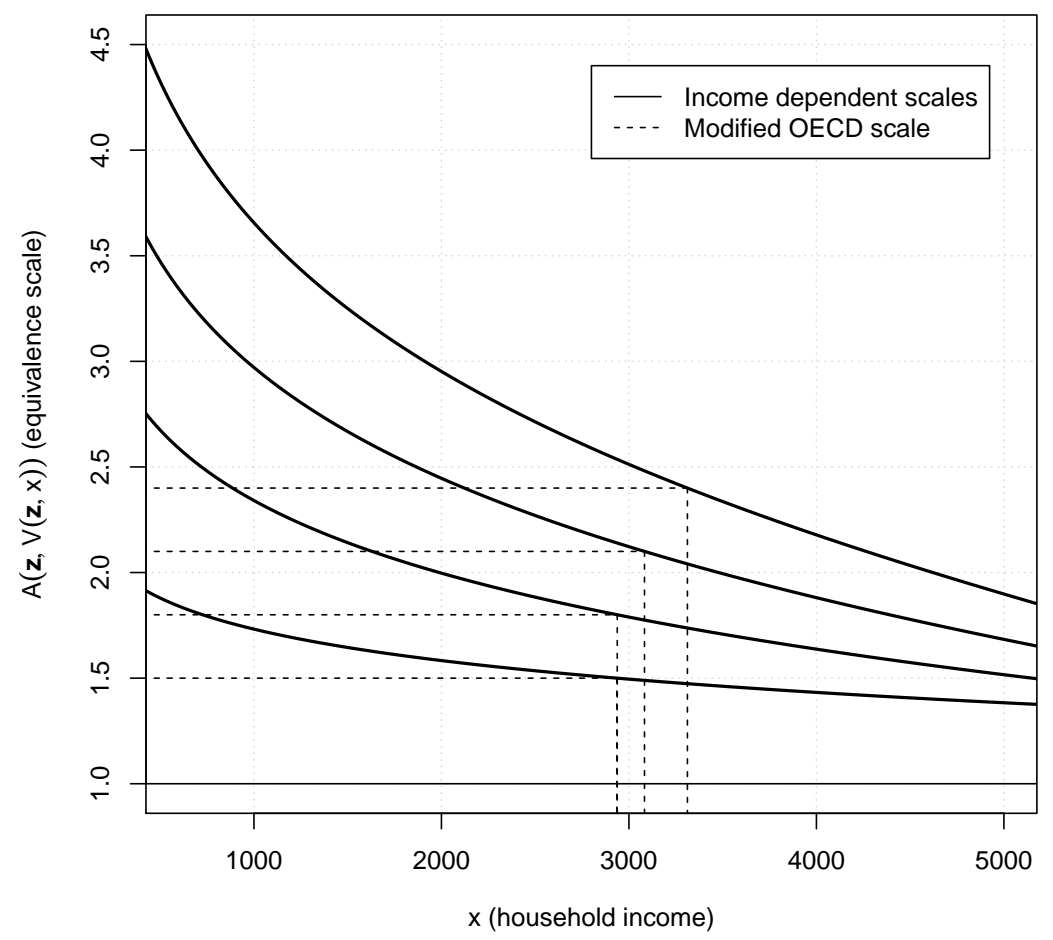

Figure 4: Income dependent and income independent equivalence scales and values $x_{\mathbf{z}}^{*}$ at which the two intersect.

Note: Calculations are based on income dependent scales for Germany derived from Koulovatianos et al. (2005a) and the modified OECD scale.

corresponding to the income dependent weight for childless couples with household income of about 2, 935 Euro. Applying the modified OECD scale to childless couples will thus treat all of them as if they had a household income of $x_{a a}^{*}=2,935$ Euro. Similarly, for couples with one child $x_{a a c}^{*}=2,938$ Euro (modified OECD scale: 1.8 ), for couples with two children $x_{\text {aacc }}^{*}=3,083$ Euro (modified OECD scale: 2.1 ), and couples with three children are treated as if they had $x_{\text {aaccc }}^{*}=3,312$ Euro (modified OECD scale 2.4).

The perspective can also be switched to looking at reference households, i.e., single persons whose income $x_{r, \mathbf{z}}^{*}$ is equivalent to the values of $x_{\mathbf{z}}^{*}$ for other household types. For the examples shown in figure 4, these incomes amount to 1,957 Euro (vis-a-vis childless couples), 1,632 Euro (couples with one child), 1, 468 Euro (couples with two children), and 1,380 Euro (couples with three children). Either way, applying income independent equivalence scales means that households of different types are treated unequal and that reference households are used which differ by income. To avoid this, incomes $x_{\mathbf{z}}^{*}\left(\right.$ or $x_{r, \mathbf{z}}^{*}$ ) could be chosen to be the same for all household types. However, this would require knowledge of the income dependent equivalence 
scale which would make the use of an income independent scale redundant.

\section{Aggregate measurement of poverty and inequal- ity}

The preceding section demonstrated inconsistency in the assessment of equivalent income at the household level, e.g. pairwise comparisons of households. In this section, we will discuss some consequences for the aggregate measurement of poverty and inequality. Specifically, we will show that given a certain density of household income, applying an income dependent and an income independent equivalence scale will always lead to different densities of equivalent income, where the difference between both densities follows certain regularities. This, in turn, leads to systematic differences in the assessment of poverty and inequality, as we will demonstrate now for the proportion of poor households and Lorenz curves.

To provide illustrative examples, we will use the German Expenditure and Income Survey 2008 (Einkommens- und Verbrauchsstichprobe; EVS), applyig both the modified OECD scale and the base dependent scale derived from Koulovatianos et al. (2005a) to this dataset. Besides the household types covered in figure 1 (single adults, childless couples, and couples with up to three children), households of single parents with up to three children will also be included. Households not belonging to one of the aforementioned types are not included in our analysis. This leaves us with 37,174 households observed in the EVS 2008 data. ${ }^{10}$

\subsection{Densities and poverty measurement}

As a general result, the true distribution of equivalent income can not be recovered using base independent scales, i.e., $\mathrm{F}(\tau) \neq \mathrm{F}_{I B}(\tau)$, where $\mathrm{F}$ denotes the cumulative distribution function ( $\mathrm{CDF}$ ) of equivalent income arising from an appropriate, income dependent equivalence scale, while $\mathrm{F}_{I B}$ denotes the $\mathrm{CDF}$ which results when a base independent scale is used. Let $\Delta_{\mathrm{F}}(\tau)=\mathrm{F}(\tau)-\mathrm{F}_{I B}(\tau)$ denote the difference between both functions. To simplify notation, we index household types by $h=1, \ldots, H$.

Proposition 4.1. Let assumptions 3.1, 3.2, and 3.3 hold. If $\tau<x_{j}^{*}$ for all $j=$ $1, \ldots, H$, then $\Delta_{\mathrm{F}}(\tau)>0$. The reverse holds if $\tau>x_{j}^{*}$ for all $j=1, \ldots, H$. Moreover, there will be some value $\tau^{*}$ such that $\Delta_{\mathrm{F}}\left(\tau^{*}\right)=0, \Delta_{\mathrm{F}}(\tau)>0$ for $\tau<\tau^{*}$, and $\Delta_{\mathrm{F}}(\tau)<0$ for $\tau>\tau^{*}$.

\footnotetext{
${ }^{10}$ Additional results relating to the issues discussed in the preceding section are reported in the appendix.
} 
The true CDF can be written as a finite mixture

$$
\mathrm{F}(\tau)=\sum_{h=1}^{H} \operatorname{Pr}(h) \int_{0}^{\tau \mathrm{A}\left[h, \mathrm{~V}\left(\mathbf{z}_{r}, \tau\right)\right]} f(u \mid h) d u
$$

where $f(x \mid h)$ is the density of household income for type- $h$ households and $\operatorname{Pr}(h)$ is the proportion of households of type $h$. In case of base independence the CDF is given by

$$
\mathrm{F}_{I B}(\tau)=\sum_{h=1}^{H} \operatorname{Pr}(h) \int_{0}^{\tau \mathrm{A}(h)} f(u \mid h) d u .
$$

Using these definitions, proposition 4.1 follows immediately.

Proposition 4.1 states that the CDFs will cross. It also implies that characterizations of the distributions are not necessarily the same. For example, if $\mu$ denotes mean equivalent income using an income dependent scale and $\mu_{I B}$ denotes mean equivalent income resulting from an income independent scale, the difference $\mu-\mu_{I B}$ is given by $\int_{0}^{x_{\max }}-\Delta_{\mathrm{F}}(t) d t$, where $x_{\max }$ is the highest observed income. Choosing a base independent scale could make sense if properties of interest were preserved, but this would again require knowledge of the base dependent scale. Moreover, the choice of a base independent scale would depend on the density of observed income, such that a specific base independent scale may preserve some properties for one income distribution but not for others.

Results for poverty measurement follow directly from proposition 4.1. Let $\gamma$ denote a given poverty line, and let $\mathrm{P}(\gamma)$ and $\mathrm{P}_{I B}(\gamma)$ be the proportions of poor households under income (in-)dependence. If $\gamma=\tau^{*}$, then $\mathrm{P}(\gamma)=\mathrm{P}_{I B}(\gamma)$, where $\tau^{*}$ is defined as in proposition 4.1. If $\gamma<\tau^{*}$, then $\mathrm{P}(\gamma)>\mathrm{P}_{I B}(\gamma)$, and if $\gamma>\tau^{*}$, then $\mathrm{P}(\gamma)<\mathrm{P}_{I B}(\gamma)$. For a given $\gamma$, this means that the proportions of the poor will only be equal if all $x_{j}^{*}$ are set such that $\tau^{*}$ equals $\gamma$. Again, this is only possible if the income dependent equivalence scale is known.

Figure 5 illustrates proposition 4.1 using data from the EVS. The CDFs of equivalent income cross at about 1, 665 Euro. Thus, for any poverty line below 1,665 Euro the proportion of poor households will be lower using the income independent modified OECD scale. As reasonable poverty lines are most likely below this threshold, applying the modified OECD scale to the EVS data will underestimate poverty compared to the income dependent scale from Koulovatianos et al. (2005a). For example, if the poverty line is set to 1,000 Euro, $12.0 \%$ of all households have an equivalent income below this threshold under the income dependent scale, while $10.4 \%$ 


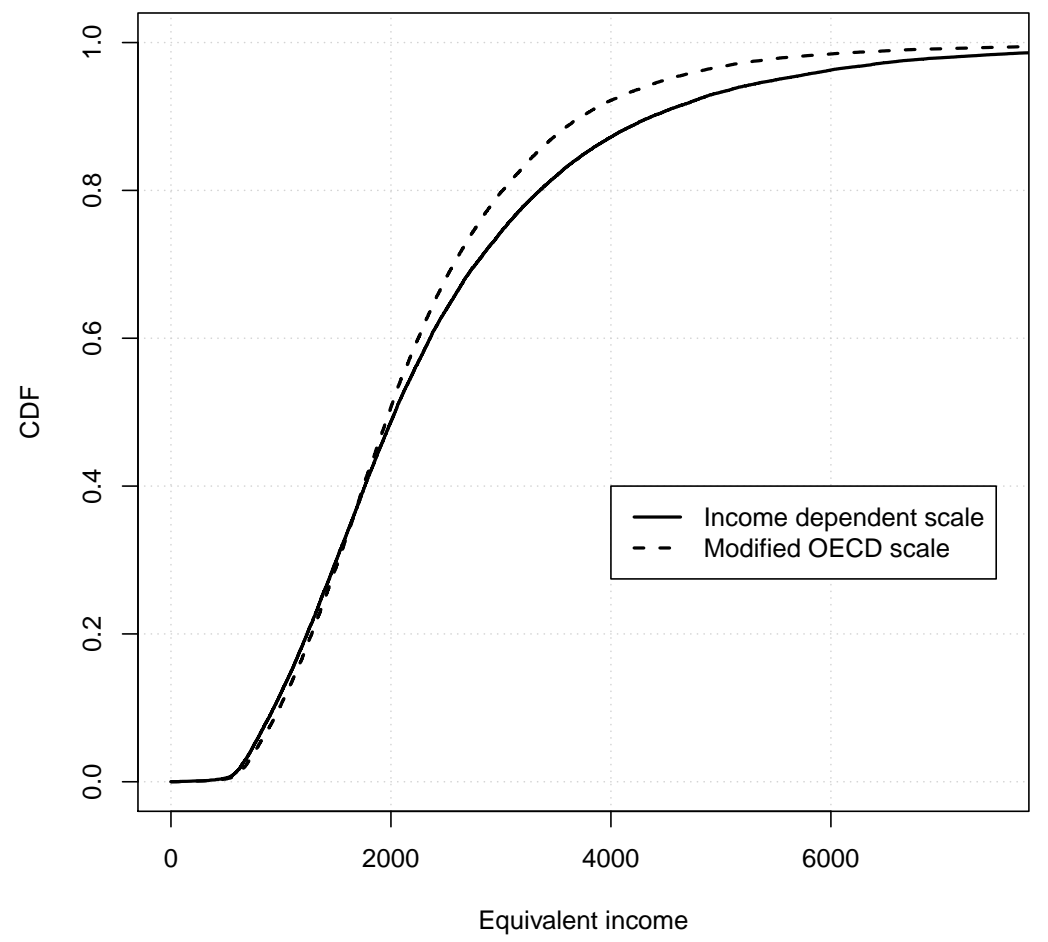

Figure 5: Cumulative distribution functions of equivalent income.

Note: Calculated using EVS data, the modified OECD scale, and the income dependent equivalence scale derived from Koulovatianos et al. (2005a).

of all households are considered poor using the modified OECD scale. Furthermore, using an poverty line that is determined endogenously may lead to larger differences. If, for instance, the poverty line is set to as $60 \%$ of median equivalent income, it amounts to 1,222 Euro in case of the income dependent scale and to 1,190 Euro in case of the modified OECD scale. The proportions of poor households amount to $19.4 \%$ and $16.6 \%$, respectively. ${ }^{11}$

\subsection{Lorenz curves and inequality}

Let $\mathrm{L}(\alpha)$ be the Lorenz curve which results from applying an income dependent equivalence scale and $\mathrm{L}_{I B}(\alpha)$ the Lorenz curve which results from an income independent scale. Mean equivalent incomes are $\mu$ and $\mu_{I B}$, respectively.

Proposition 4.2. Let assumptions 3.1, 3.2, and 3.3 hold. If $\mu \geq \mu_{I B}$, then $\mathrm{L}(\alpha) \leq$ $\mathrm{L}_{I B}(\alpha)$. If $\mu<\mu_{I B}$, then Lorenz curves cross and $\mathrm{L}(\alpha) \lessgtr \mathrm{L}_{I B}(\alpha)$.

\footnotetext{
${ }^{11}$ Standard errors calculated using the method of Zheng (2001) are rather similar, though, and amount to about 0.002 in both cases.
} 


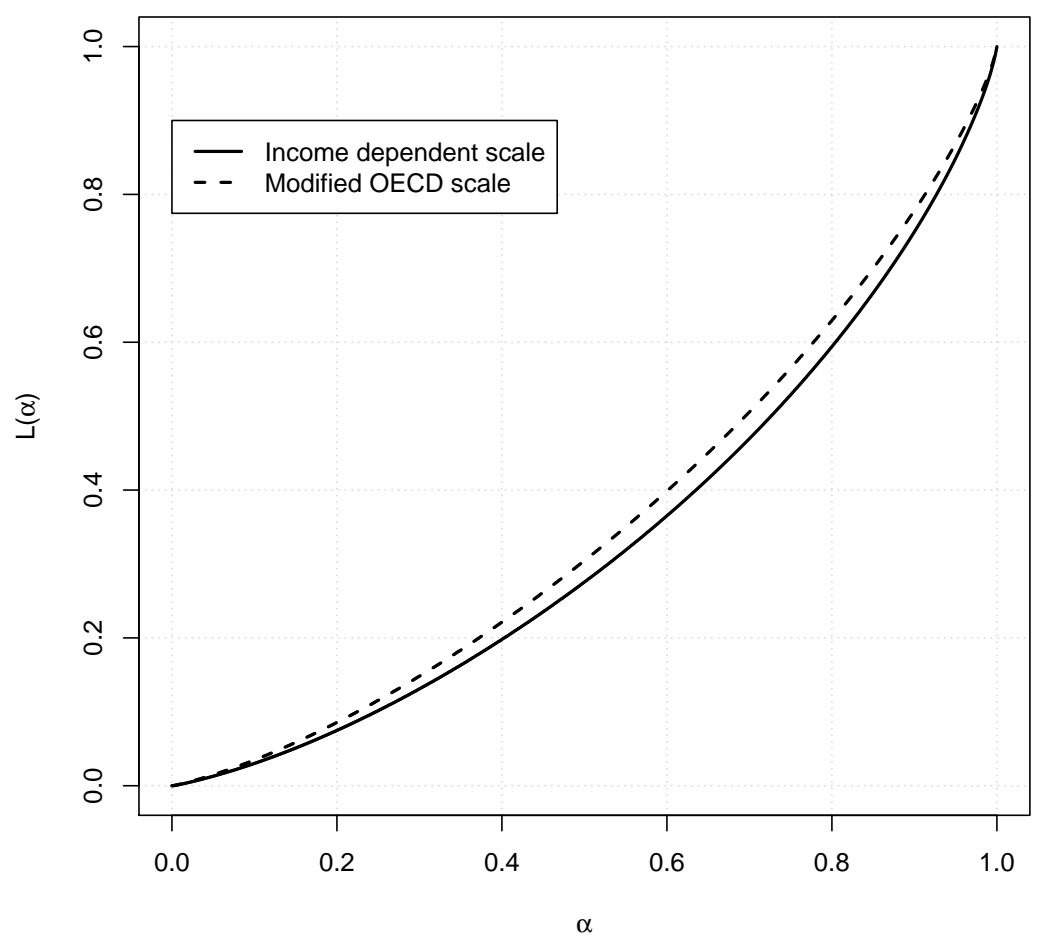

Figure 6: Lorenz curves for equivalent income.

Note: Calculated using EVS data, the modified OECD scale, and the income dependent equivalence scale derived from Koulovatianos et al. (2005a).

This follows from the results in Atkinson (1970) and from proposition 4.1. A proof for the case of $\mu=\mu_{I B}$ is given in the appendix. Proposition 4.2 implies that income independent scales either show less inequality than income dependent scales, or a relationship of this kind can not be clearly established. In the first case, inequality measures like the Gini coefficient will always be lower for income independent scales, while the second case allows no such clear cut conclusions. This is illustrated by the results of Aaberge and Melby (1998), Donaldson and Pendakur (2006), Balli and Tiezzi (2013), or Juhasz and Biewen (2014) who arrive at different conclusions regarding the effect of base independent versus base dependent scales on the Gini coefficient.

Figure 6 shows Lorenz curves calculated for the EVS data using the income dependent equivalence scale derived from Koulovatianos et al. (2005a) and the modified OECD scale. Mean equivalent income amounts to 2, 444 Euro and 2, 243 Euro, respectively. Because of this, the distribution of equivalent income arising from the modified OECD scale Lorenz-dominates the distribution arising from the income dependent equivalence scale, i.e., $\mathrm{L}(\alpha) \leq \mathrm{L}_{I B}(\alpha)$. The Gini coefficient amounts to 
0.33 and 0.28 , respectively, and therefore differs considerably. ${ }^{12}$

\section{Conclusions}

This paper explored the systematic relationship between results on inequality and poverty deriving from income independent and income dependent equivalence scales. Not surprisingly, equivalent income at the household level differs between the two cases, and the relative difference is income dependent itself. Moreover, and less obviously, the ordering of households by equivalent income may differ, i.e., it depends on the type of the equivalence scale applied which of two households is better off in terms of equivalent income. As a consequence transfers which are progressive under an income dependent equivalence scale may be regressive if an income independent equivalence scale is applied. These results hold for any combination of income (in-)dependent equivalence scales under quite general conditions. Because of this, assessments of poverty and inequality at the aggregate level will always differ except for some special cases. In our example using German micro data, the application of an income dependent equivalence scale leads to considerably higher figures of poverty and inequality than the application of an income independent equivalence scale.

Our findings explain the results of sensitivity analyses reported in the literature, which show marked differences of measures of poverty and inequality depending on the type of the equivalence scale that is used. Since there is ample empirical evidence that equivalence scales are in fact income dependent, our findings challenge the widespread use of income independent equivalence scales like the modified OECD scale. Researchers should apply income dependent equivalence scales whenever this is possible. The same holds for policy makers, as equivalence scales are also used to inform policy decisions.

\footnotetext{
${ }^{12}$ Again, standard errors are quite similar, amounting to 0.001 in both cases, and were calculated using linearization as described in Langel and Tille (2013).
} 


\section{A Proof of proposition 3.2}

The proof of proposition 3.2 follows directly from lemmas A.1, A.2, and A.3. Lemma A.1 shows the conditions which are required for inversions, viz. $\mathrm{C}\left[\mathbf{z}_{r}, \mathrm{~V}\left(\mathbf{z}_{2}, x_{2}\right)\right]>$ $\mathrm{C}\left[\mathbf{z}_{r}, \mathrm{~V}\left(\mathbf{z}_{1}, x_{1}\right)\right]$ and $\tilde{\mathrm{C}}\left[\mathbf{z}_{r}, \mathrm{~V}\left(\mathbf{z}_{2}, x_{2}\right)\right]<\tilde{\mathrm{C}}\left[\mathbf{z}_{r}, \mathrm{~V}\left(\mathbf{z}_{1}, x_{1}\right)\right]$. For inversions to occur, two incomes $x_{1}$ and $x_{2}$ are needed for which values $c\left(x_{1}\right) \neq c\left(x_{2}\right)$ exist fulfilling certain requirements. Lemma A.2 proves the existence of $c(x)$ for any $x$, while lemma A.3 shows the conditions under which $c\left(x_{1}\right) \neq c\left(x_{2}\right)$.

Lemma A.1. Let assumptions 3.1, 3.2, and 3.4 hold. If for any two household types $\mathbf{z}_{1}$ and $\mathbf{z}_{2}$ two incomes $x^{\prime}$ and $x^{\prime \prime}$ exist where for each of these incomes there is a value $c(x)$ with $\mathrm{A}\left[\mathbf{z}_{2}, \mathrm{~V}\left(\mathbf{z}_{2}, c(x) x\right)\right] / \mathrm{A}\left[\mathbf{z}_{1}, \mathrm{~V}\left(\mathbf{z}_{1}, x\right)\right]=c(x)$ and $c\left(x^{\prime}\right) \neq c\left(x^{\prime \prime}\right)$, then inversions will occur.

Proof. Without loss of generality, assume that the needs of households of type $\mathbf{z}_{1}$ are smaller than those of households of type $\mathbf{z}_{2}$ and thus $\mathrm{A}\left[\mathbf{z}_{1}, \mathrm{~V}\left(\mathbf{z}_{1}, y\right)\right] \leq \mathrm{A}\left[\mathbf{z}_{2}, \mathrm{~V}\left(\mathbf{z}_{2}, y\right)\right]$ by assumption 3.4. Let $x^{\prime} \in \mathbb{R}_{+}$be some income with $c\left(x^{\prime}\right) \in \mathbb{R}_{+}$, such that $\mathrm{A}\left[\mathbf{z}_{2}, \mathrm{~V}\left(\mathbf{z}_{2}, c\left(x^{\prime}\right) x^{\prime}\right)\right] / \mathrm{A}\left[\mathbf{z}_{1}, \mathrm{~V}\left(\mathbf{z}_{1}, x^{\prime}\right)\right]=c\left(x^{\prime}\right)$. Let $b$ denote the ratio of income independent scales $\mathrm{A}\left(\mathbf{z}_{2}\right) / \mathrm{A}\left(\mathbf{z}_{1}\right)$. Assume that $b>c\left(x^{\prime}\right)$. In this case there will be some positive value $\delta$ for which $c\left(x^{\prime}\right)<c\left(x^{\prime}\right)+\delta<b$. From assumption 3.2, it follows that

$$
\frac{\mathrm{A}\left[\mathbf{z}_{2}, \mathrm{~V}\left(\mathbf{z}_{2},\left[c\left(x^{\prime}\right)+\delta\right] x^{\prime}\right)\right]}{\mathrm{A}\left[\mathbf{z}_{1}, \mathrm{~V}\left(\mathbf{z}_{1}, x^{\prime}\right)\right]}<c\left(x^{\prime}\right)<c\left(x^{\prime}\right)+\delta<b .
$$

Thus, for $x_{2}=\left[c\left(x^{\prime}\right)+\delta\right] x^{\prime}$ and $x_{1}=x^{\prime}$, inequality

$$
\frac{\mathrm{A}\left[\mathbf{z}_{2}, \mathrm{~V}\left(\mathbf{z}_{2}, x_{2}\right)\right]}{\mathrm{A}\left[\mathbf{z}_{1}, \mathrm{~V}\left(\mathbf{z}_{1}, x_{1}\right)\right]}<\frac{x_{2}}{x_{1}}<\frac{\mathrm{A}\left(\mathbf{z}_{2}\right)}{\mathrm{A}\left(\mathbf{z}_{1}\right)}
$$

holds, from which

$$
\mathrm{C}\left[\mathbf{z}_{r}, \mathrm{~V}\left(\mathbf{z}_{2}, x_{2}\right)\right]>\mathrm{C}\left[\mathbf{z}_{r}, \mathrm{~V}\left(\mathbf{z}_{1}, x_{1}\right)\right] \text { and } \tilde{\mathrm{C}}\left[\mathbf{z}_{r}, \mathrm{~V}\left(\mathbf{z}_{2}, x_{2}\right)\right]<\tilde{\mathrm{C}}\left[\mathbf{z}_{r}, \mathrm{~V}\left(\mathbf{z}_{1}, x_{1}\right)\right]
$$

follow. Similar arguments can be made to show that inversions occur if $b<c\left(x^{\prime}\right)$, with all inequalities in equations (A.1), (A.2), and (A.3) being reversed. Inversions will not occur only if $b=c\left(x^{\prime}\right)$. Now let $x^{\prime \prime} \neq x^{\prime}$ be another income with $c\left(x^{\prime \prime}\right)$, such that $\mathrm{A}\left[\mathbf{z}_{2}, \mathrm{~V}\left(\mathbf{z}_{2}, c\left(x^{\prime \prime}\right) x^{\prime \prime}\right)\right] / \mathrm{A}\left[\mathbf{z}_{1}, \mathrm{~V}\left(\mathbf{z}_{1}, x^{\prime \prime}\right)\right]=c\left(x^{\prime \prime}\right)$. Again, a necessary and sufficient condition for no inversions to occur is $b=c\left(x^{\prime \prime}\right)$, which requires $c\left(x^{\prime}\right)=c\left(x^{\prime \prime}\right)$ and proves the lemma.

Lemma A.2. Let assumptions 3.1, 3.2, and 3.4 hold. For any two household types 
$\mathbf{z}_{1}$ and $\mathbf{z}_{2}$ a value $c(x)$ exists for each income $x$, such that

$$
c(x)=\mathrm{A}\left[\mathbf{z}_{2}, \mathrm{~V}\left(\mathbf{z}_{2}, c(x) x\right)\right] / \mathrm{A}\left[\mathbf{z}_{1}, \mathrm{~V}\left(\mathbf{z}_{1}, x\right)\right]
$$

Proof. Without loss of generality, assume again that the needs of type- $\mathbf{z}_{1}$ households

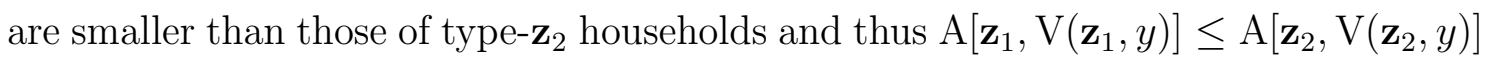
by assumption 3.4. For $c=1$, the inequality $\mathrm{A}\left[\mathbf{z}_{2}, \mathrm{~V}\left(\mathbf{z}_{2}, c x\right)\right] / \mathrm{A}\left[\mathbf{z}_{1}, \mathrm{~V}\left(\mathbf{z}_{1}, x\right)\right] \geq c$ holds. Now two cases can be distinguished. If for some $x$ and $c=1$, the strict equality $\mathrm{A}\left[\mathbf{z}_{2}, \mathrm{~V}\left(\mathbf{z}_{2}, c x\right)\right] / \mathrm{A}\left[\mathbf{z}_{1}, \mathrm{~V}\left(\mathbf{z}_{1}, x\right)\right]=c$ holds, $c(x)$ exists and equals 1 . If for some $x$ and $c=1$ the strict inequality $\mathrm{A}\left[\mathbf{z}_{2}, \mathrm{~V}\left(\mathbf{z}_{2}, c x\right)\right] / \mathrm{A}\left[\mathbf{z}_{1}, \mathrm{~V}\left(\mathbf{z}_{1}, x\right)\right]>c$ holds, then $\mathrm{A}\left[\mathbf{z}_{2}, \mathrm{~V}\left(\mathbf{z}_{2}, x\right)\right] / \mathrm{A}\left[\mathbf{z}_{1}, \mathrm{~V}\left(\mathbf{z}_{1}, x\right)\right]>c(x)>1$ because of assumption 3.2. The existence of $c(x)$ follows immediately from assumption 3.2 and the intermediate value theorem.

Lemma A.3. Let assumptions 3.1, 3.2, and 3.4 hold. For any two household types $\mathbf{z}_{1}$ and $\mathbf{z}_{2}$ inversions will not occur only if $\mathrm{A}\left[\mathbf{z}_{1}, \mathrm{~V}\left(\mathbf{z}_{1}, x\right)\right]=\mathrm{B}\left(\mathbf{z}_{1}\right) \mathrm{K}(x), \mathrm{A}\left[\mathbf{z}_{2}, \mathrm{~V}\left(\mathbf{z}_{2}, x\right)\right]=$ $\mathrm{B}\left(\mathbf{z}_{2}\right) \mathrm{K}\left[\mathrm{B}\left(\mathbf{z}_{1}\right) / \mathrm{B}\left(\mathbf{z}_{2}\right) x\right]$, and $\mathrm{B}\left(\mathbf{z}_{2}\right) / \mathrm{B}\left(\mathbf{z}_{1}\right)=\mathrm{A}\left(\mathbf{z}_{2}\right) / \mathrm{A}\left(\mathbf{z}_{1}\right)$. If $\mathbf{z}_{1}=\mathbf{z}_{r}$ and $\mathbf{z}_{2} \neq \mathbf{z}_{r}$, inversions will always occur.

Proof. By lemma A.1 for any two incomes $x^{\prime}$ and $x^{\prime \prime}$ the equality $c\left(x^{\prime}\right)=c\left(x^{\prime \prime}\right)=$ $\mathrm{A}\left(\mathbf{z}_{2}\right) / \mathrm{A}\left(\mathbf{z}_{1}\right)$ must hold for inversions not to occur, or equivalently

$$
\frac{\mathrm{A}\left[\mathbf{z}_{2}, \mathrm{~V}\left(\mathbf{z}_{2}, \mathrm{~A}\left(\mathbf{z}_{2}\right) / \mathrm{A}\left(\mathbf{z}_{1}\right) x^{\prime}\right)\right]}{\mathrm{A}\left[\mathbf{z}_{1}, \mathrm{~V}\left(\mathbf{z}_{1}, x^{\prime}\right)\right]}=\frac{\mathrm{A}\left[\mathbf{z}_{2}, \mathrm{~V}\left(\mathbf{z}_{2}, \mathrm{~A}\left(\mathbf{z}_{2}\right) / \mathrm{A}\left(\mathbf{z}_{1}\right) x^{\prime \prime}\right)\right]}{\mathrm{A}\left[\mathbf{z}_{1}, \mathrm{~V}\left(\mathbf{z}_{1}, x^{\prime \prime}\right)\right]}=\frac{\mathrm{A}\left(\mathbf{z}_{2}\right)}{\mathrm{A}\left(\mathbf{z}_{1}\right)} .
$$

This also implies

$$
\frac{\mathrm{A}\left[\mathbf{z}_{1}, \mathrm{~V}\left(\mathbf{z}_{1}, x^{\prime \prime}\right)\right]}{\mathrm{A}\left[\mathbf{z}_{1}, \mathrm{~V}\left(\mathbf{z}_{1}, x^{\prime}\right)\right]}=\frac{\mathrm{A}\left[\mathbf{z}_{2}, \mathrm{~V}\left(\mathbf{z}_{2}, \mathrm{~A}\left(\mathbf{z}_{2}\right) / \mathrm{A}\left(\mathbf{z}_{1}\right) x^{\prime \prime}\right)\right]}{\mathrm{A}\left[\mathbf{z}_{2}, \mathrm{~V}\left(\mathbf{z}_{2}, \mathrm{~A}\left(\mathbf{z}_{2}\right) / \mathrm{A}\left(\mathbf{z}_{1}\right) x^{\prime}\right)\right]} .
$$

Setting $\mathrm{A}\left[\mathbf{z}_{1}, \mathrm{~V}\left(\mathbf{z}_{1}, x\right)\right]=\mathrm{B}\left(\mathbf{z}_{1}\right) \mathrm{K}(x), \mathrm{A}\left[\mathbf{z}_{2}, \mathrm{~V}\left(\mathbf{z}_{2}, x\right)\right]=\mathrm{B}\left(\mathbf{z}_{2}\right) \mathrm{K}\left[\mathrm{B}\left(\mathbf{z}_{1}\right) / \mathrm{B}\left(\mathbf{z}_{2}\right) x\right]$, and $\mathrm{B}\left(\mathbf{z}_{2}\right) / \mathrm{B}\left(\mathbf{z}_{1}\right)=\mathrm{A}\left(\mathbf{z}_{2}\right) / \mathrm{A}\left(\mathbf{z}_{1}\right)$, equations (A.5) and (A.6) will hold for all $x^{\prime}$ and $x^{\prime \prime}$. These shape restrictions are necessary. Any other shapes of income dependent equivalence scales can be captured by either letting $\mathrm{K}$ depend on $\mathbf{z}, \mathrm{K}(x, \mathbf{z})$, or by letting $\mathrm{B}$ depend on $x, \mathrm{~B}(x, \mathbf{z})$. If $\mathrm{K}$ is a function of $\mathbf{z}$, there has to be at least one income $y$ for which $\mathrm{K}\left(y, \mathbf{z}_{1}\right) \neq \mathrm{K}\left(y, \mathbf{z}_{2}\right)$, and equation (A.5) would not hold. If $\mathrm{B}$ depends on income, there have to be at least two incomes $y^{\prime}$ and $y^{\prime \prime}$ for which $\mathrm{B}\left(y^{\prime}, \mathbf{z}_{1}\right) \neq \mathrm{B}\left(y^{\prime \prime}, \mathbf{z}_{1}\right)$ or $\mathrm{B}\left(y^{\prime}, \mathbf{z}_{2}\right) \neq \mathrm{B}\left(y^{\prime \prime}, \mathbf{z}_{2}\right)$, and equation (A.6) would not hold. If $\mathrm{B}\left(\mathbf{z}_{2}\right) / \mathrm{B}\left(\mathbf{z}_{1}\right)$ would not equal $\mathrm{A}\left(\mathbf{z}_{2}\right) / \mathrm{A}\left(\mathbf{z}_{1}\right)$, equation (A.5) would not hold. A special case is $\mathbf{z}_{1}=\mathbf{z}_{r}$, as assumption 2.1 leads to

$$
\mathrm{A}\left[\mathbf{z}_{2}, \mathrm{~V}\left(\mathbf{z}_{2}, \mathrm{~A}\left(\mathbf{z}_{2}\right) / \mathrm{A}\left(\mathbf{z}_{1}\right) x^{\prime}\right)\right]=\mathrm{A}\left[\mathbf{z}_{2}, \mathrm{~V}\left(\mathbf{z}_{2}, \mathrm{~A}\left(\mathbf{z}_{2}\right) / \mathrm{A}\left(\mathbf{z}_{1}\right) x^{\prime \prime}\right)\right]=\frac{\mathrm{A}\left(\mathbf{z}_{2}\right)}{\mathrm{A}\left(\mathbf{z}_{1}\right)},
$$


which is ruled out by assumption 3.2. In this case $c\left(x^{\prime}\right) \neq c\left(x^{\prime \prime}\right)$ for all $x^{\prime} \neq x^{\prime \prime}$.

\section{B Proof of proposition 4.2}

Proof. Let assumptions 3.1, 3.2, and 3.3 hold. Assume that $\mu=\mu_{I B}$. Conditional means are also assumed to be equal, i.e., $\mu_{h}=\mu_{h, I B}$. Let $\gamma(\alpha)$ and $\gamma_{I B}(\alpha)$ with $\alpha \in[0,1]$ be the quantile functions of the distributions of equivalent income, i.e., $\mathrm{F}[\gamma(\alpha)]=\mathrm{F}_{I B}\left[\gamma_{I B}(\alpha)\right]=\alpha$, which are assumed to be strictly increasing in $\alpha$. Note that necessarily

$$
\gamma(\alpha) \mathrm{A}\left[h, \mathrm{~V}\left(\mathbf{z}_{r}, \gamma(\alpha)\right)\right]=\gamma_{I B}(\alpha) \mathrm{A}(h)
$$

for all $h$, which follows from the definition of the CDFs given in equations (4.1) and (4.2). Let $x(\alpha, h)$ denote the result of (B.1) for some $\alpha$ and $h$. Using base dependent scales the Lorenz curve can be written as

$$
\mathrm{L}(\alpha)=\frac{\sum_{h=1}^{H} \operatorname{Pr}(h) \int_{0}^{x(\alpha, h)} t \mathrm{~A}\left[h, \mathrm{~V}\left(\mathbf{z}_{r}, t\right)\right]^{-1} f(t \mid h) d t}{\mu},
$$

where $f(t \mid h)$ is the density of observed income for households of type $h$ and $\mu$ is mean equivalent income. In case of base independence, the Lorenz curve is given by

$$
\mathrm{L}_{I B}(\alpha)=\frac{\sum_{h=1}^{H} \operatorname{Pr}(h) \int_{0}^{x(\alpha, h)} t \mathrm{~A}(h)^{-1} f(t \mid h) d t}{\mu} .
$$

Let

$$
\Delta_{L}(\alpha)=\frac{\sum_{h=1}^{H} \operatorname{Pr}(h) \int_{0}^{x(\alpha, h)} t\left(\mathrm{~A}\left[h, \mathrm{~V}\left(\mathbf{z}_{r}, t\right)\right]^{-1}-\mathrm{A}(h)^{-1}\right) f(t \mid h) d t}{\mu}
$$

denote the difference between both Lorenz curves, $\mathrm{L}(\alpha)-\mathrm{L}_{I B}(\alpha)$. By definition, $\mathrm{L}(0)=\mathrm{L}_{I B}(0)=0$ and $\mathrm{L}(1)=\mathrm{L}_{I B}(1)=1$. Therefore $\Delta_{L}(0)=0$ and $\Delta_{L}(1)=0$. Since for all functions

$$
l_{h}(\alpha)=\int_{0}^{x(\alpha, h)} t\left(\mathrm{~A}\left[h, \mathrm{~V}\left(\mathbf{z}_{r}, t\right)\right]^{-1}-\mathrm{A}(h)^{-1}\right) f(t \mid h) d t
$$

the statement $0 \geq l_{h}(\alpha)$ is true, this carries over to their convex combination in $\Delta_{L}(\alpha)$, and proposition 4.2 follows. 


\section{Additional empirical results for section 3}

This appendix provides empirical results based on EVS data which demonstrate the importance of the findings of sections 3.2 and 3.3.

Table 1 includes additional results relating to absolute levels of equivalent income as discussed in section 3.2. It shows minimum, mean, and maximum relative bias $\mathrm{B}\left(x, x_{\mathbf{z}}^{*}, \mathbf{z}\right)$ by household type using the EVS data described in section 4 . Proportions of households for which the relative bias is below 0.9 or higher than 1.1 are also shown. Relative bias ranges between 0.62 and 1.91 for couples with one child; mean relative bias equals $0.92{ }^{13}$ For $44 \%$ of couples with one child relative bias is less than 0.9 , i.e., equivalent income is grossly underestimated, while for $9 \%$ the relative bias exceeds 1.1 and equivalent income is grossly overestimated. The results in table 1 provide strong evidence that relative bias can in fact be large in an empirical setting.

Table 2 displays results relating to the ordering of equivalent income as discussed in section 3.3. For each pair of household types, it shows the proportion of inversions as defined in proposition 3.2. For example, in $2 \%$ of possible comparisons between households of single adults and households of couples, the ordering of equivalent incomes using the modified OECD scale differs from the ordering of equivalent incomes based on the income dependent scale derived from Koulovatianos et al. (2005a). Depending on the pairings under consideration, proportions range from 0.01 to 0.11 . This means that inversions are negligible for some pairings, while for others they are not. The results clearly indicate that inversions can occur quite often in an empirical setting.

\footnotetext{
${ }^{13}$ Note that mean relative bias close to 1 does not imply that mean equivalent income using the equivalence scale from Koulovatianos et al. (2005a) or using the modified OECD scale are necessarily equal. For example, for childless couples mean equivalent incomes amount to 2,661 Euro and 2,501 Euro, respectively.
} 
Table 1: Descriptive statistics for relative bias by household type

\begin{tabular}{lrrrrr}
\hline \hline Household type & Minimum & Mean & Maximum & $\tilde{\mathrm{B}}<0.9$ & $\tilde{\mathrm{B}}>1.1$ \\
\hline aa & 0.73 & 0.98 & 1.46 & 0.12 & 0.05 \\
aac & 0.62 & 0.92 & 1.91 & 0.44 & 0.09 \\
aacc & 0.52 & 0.85 & 1.78 & 0.62 & 0.06 \\
aaccc & 0.47 & 0.82 & 1.40 & 0.65 & 0.08 \\
ac & 0.77 & 1.03 & 1.55 & 0.11 & 0.25 \\
acc & 0.63 & 0.99 & 1.26 & 0.26 & 0.23 \\
accc & 0.53 & 0.99 & 1.27 & 0.25 & 0.24 \\
\hline \hline
\end{tabular}

Note: Letter 'a' indicates an adult household member and 'c' a child. For instance, 'aac' is used for couples with one child and 'acc' is used for single parents with two children.

Table 2: Proportion of transfers which are progressive (regressive) using an income dependent equivalence scale and regressive (progressive) using the modified OECD scale.

\begin{tabular}{lrrrrrrrr}
\hline \hline & a & aa & aac & aacc & aaccc & ac & acc & accc \\
\hline a & & & & & & & & \\
aa & 0.02 & & & & & & & \\
aac & 0.04 & 0.04 & & & & & & \\
aacc & 0.07 & 0.08 & 0.04 & & & & & \\
aaccc & 0.09 & 0.11 & 0.08 & 0.04 & & & & \\
ac & 0.03 & 0.02 & 0.01 & 0.02 & 0.04 & & & \\
acc & 0.05 & 0.04 & 0.03 & 0.01 & 0.02 & 0.02 & & \\
accc & 0.06 & 0.05 & 0.04 & 0.03 & 0.01 & 0.03 & 0.01 \\
\hline \hline
\end{tabular}

Note: Calculated using the income dependent equivalence scale derived from Koulovatianos et al. (2005a) and the modified OECD scale. 


\section{References}

Aaberge, R., Melby, I., 1998. The sensitivity of income inequality to choice of equivalence scales. Review of Income and Wealth 44, 565-569.

Allison, P. D., 1978. Measures of inequality. American Sociological Review 43, 865880.

Atkinson, A. B., 1970. On the measurement of inequality. Journal of Economic Theory 2, 244-263.

Balli, F., Tiezzi, S., 2013. Declining equivalence scales and cost of children: Evidence and implications for inequality measurement. The B.E. Journal of Economic Analysis \& Policy 13, 761-782.

Blackorby, C., Donaldson, D., 1993. Adult-equivalence scales and the economic implementation of interpersonal comparisons of well being. Social Choice and Welfare 10, 335-361.

Blundell, R., Lewbel, A., 1991. The information content of equivalence scales. Journal of Econometrics 50, 49-68.

Buhmann, B., Rainwater, L., Schmaus, G., Smeeding, T. M., 1988. Equivalence scales, well-being, inequality, and poverty: Sensitivity estimates across ten countries using the Luxembuorg Income Study (LIS) database. Review of Income and Wealth 34, $115-142$.

Conniffe, D., 1992. The non-constancy of equivalence scales. Review of Income and Wealth 38, 429-442.

Coulter, F. A. E., Cowell, F. A., Jenkins, S. P., 1992. Equivalence scale relativities and the extent of inequality and poverty. Economic Journal 102, 1067-1082.

de Ree, J., Alessie, R., Pradhan, M., 2013. The price and utility dependence of equivalence scales: Evidence from Indonesia. Journal of Public Economics 97, $272-281$.

Deaton, A., Muellbauer, J., 1980. An almost ideal demand system. American Economic Review 70, 312-326.

Dickens, R., Fry, V., Pashardes, P., 1993. Non-linearities and equivalence scales. Economic Journal 103, 359-368.

Donaldson, D., Pendakur, K., 2004. Equivalent-expenditure functions and expenditure-dependent equivalence scales. Journal of Public Economics 88, 175208.

Donaldson, D., Pendakur, K., 2006. The identification of fixed costs from consumer behaviour. Journal of Business and Economic Statistics 24, 255-265.

Ebert, U., Moyes, P., 2003. Equivalence scales reconsidered. Econometrica 71, 319 343.

Glewwe, P., 1991. Household equivalence scales and the measurement of inequality: Transfers from the poor to the rich could decrease inequality. Journal of Public Economics 44, 211-216.

Gozalo, P., 1997. Nonparametric bootstrap analysis with applications to demographic effects in demand functions. Journal of Econometrics 81, 357-393.

Hagenaars, A., de Vos, K., Zaidi, M. A., 1994. Poverty statistics in the late 1980s: Research based on micro-data, Luxembourg: Office for Official Publications of the European Communities. 
Jones, A., O'Donnel, O., 1995. Equivalence scales and the costs of disability. Journal of Public Economics 56, 273-289.

Juhasz, A., Biewen, M., 2014. Direct estimation of equivalence scales, working paper.

Kalwij, A., Alessie, R., Fontein, P., 1998. Household commodity demand and demographics in the Netherlands: A microeconometric analysis. Journal of Population Economics 11, 551-577.

Koohi-Kamali, F., 2013. Estimation of equivalence scales under convertible rationing. Review of Income and Wealth 59, 113-132.

Koulovatianos, C., Schröder, C., Schmidt, U., 2005a. On the income dependence of equivalence scales. Journal of Public Economics 89, 967-996.

Koulovatianos, C., Schröder, C., Schmidt, U., 2005b. Properties of equivalence scales in different countries. Journal of Economics 86, 19-27.

Lancaster, G., Ray, R., 1998. Comparison of alternative models of household equivalence scales: The Australian evidence on unit record data. Economic Record 74, $1-14$.

Langel, M., Tille, Y., 2013. Variance estimation of the Gini index: Revisiting a result several times published. Journal of the Royal Statistical Society, Series A 176, $521-540$.

Lewbel, A., 1989. Household equivalence scales and welfare comparisons. Journal of Public Economics 39, 377-391.

Lluch, C., 1973. The extended linear expenditure system. European Economic Review 4, 21-32.

Lyssiotou, P., 2003. On estimating the cost of characteristics indices from consumer demand analysis. Canadian Journal of Economics 36, 326-349.

Nelson, J. A., 1993. Household equivalence scales: Theory versus policy? Journal of Labor Economics 11, 471-493.

Ott, N., 1992. Intrafamily Bargaining and Household Decisions. Springer, New York. Pashardes, P., 1995. Equivalence scales in a rank-3 demand system. Journal of Public Economics 58, 143-158.

Pendakur, K., 1999. Semiparametric estimates and tests of base-independent equivalence scales. Journal of Econometrics 88, 1-40.

Pendakur, K., 2002. Taking prices seriously in the measurement of inequality. Journal of Public Economics 86, 47-69.

Phipps, S. A., Burton, P. S., 1995. Sharing within families: Implications for the measurement of poverty among individuals in Canada. The Canadian Journal of Economics 28, 177-204.

Plug, E. J. S., van Praag, B., 1995. Family equivalence scales with a narrow and broad welfare context. Journal of Income Distribution 4, 171-186.

Schröder, C., 2004. Variable Income Equivalence Scales: An Empirical Approach. Springer.

Szelky, M., Lustig, N., Cumpa, M., Meja, J. A., 2004. Do we know how much poverty there is? Oxford Development Studies 32, 523-558.

Zheng, B., 1997. Aggregate poverty measures. Journal of Economic Surveys 11, $123-162$.

Zheng, B., 2001. Statistical inference for poverty measures with relative poverty lines. Journal of Econometrics 101, 337-356. 